\title{
FAECAL CARRIAGE OF AEROBIC GRAM-NEGATIVE BACILLI AND DRUG RESISTANCE OF ESCHERICHIA COLI IN DIFFERENT AGE-GROUPS IN DUTCH URBAN COMMUNITIES
}

\author{
J. E. Degener, A. C. W. Smit, M. F. Michel \\ H. A. VAlKenBurG* AND L. MulleR* \\ Department of Clinical Microbiology and Antimicrobial Therapy and * Department of \\ Epidemiology, Medical Faculty, Erasmus University Rotterdam, P.O. Box 1738, 3000 \\ DR Rotterdam, The Netherlands
}

\begin{abstract}
SUMmary. Faecal carriage rates for aerobic gram-negative bacilli and for antibiotic-resistant Escherichia coli were determined in samples of the Dutch urban population. Of the 741 people studied, 64 were under 1 year old (infants), 53 were 1-5 years old, and there were approximately 200 in each of the age-ranges 6-17 years, 18-49 years and 50-80 years. Carriage rates of $E$. coli were similar $(87-93 \%$ ) in all age groups, but Klebsiella and Enterobacter species were found more often in specimens from infants and young children than in those from older people. $E$. coli strains resistant to tetracycline, ampicillin, or sulphamethoxazole or to any one or more of them were detected in $42 \%, 26 \%, 46 \%$ and $66 \%$ respectively of the specimens found to contain E. coli. The corresponding figures for the finding of $E$. coli populations that were predominantly resistant to tetracycline, ampicillin or sulphamethoxazole were $12 \%, 6 \%$ and $20 \%$. The frequency of resistance to any of these drugs was not related to age or sex of the subjects. All $E$. coli isolates were sensitive to gentamicin. Among the 577 subjects aged 6-80 years from whose samples $E$. coli was isolated were 19 who had taken antibacterial drugs in the previous 30 days and 11 who were involved in cattle farming; carriage rates for tetracycline-resistant and sulphonamide-resistant $E$. coli were significantly higher among these 30 than in the other 547.
\end{abstract}

\section{INTRODUCTION}

The alimentary tract is the normal habitat of enterobacteria and Pseudomonas species. It is the main source from which infections with these organisms originate. In general practice these are usually urinary tract infections. Intra-abdominal infections, wound sepsis and pneumonia occur mainly in hospital. If antibiotic-resistant gram-negative bacilli colonise the alimentary tract, they may be responsible for such infections (Brumfitt et al., 1971; Grüneberg and Shaw, 1976; Cooke et al., 1979, 1980). There is much concern about the emergence of resistant enterobacterial strains 
in the hospital environment, but little is known of their prevalence in the community. We have tried to define the present level of resistant faecal flora by an epidemiological survey in two urban communities in The Netherlands. The results are discussed in the light of comparable surveys in Great Britain and The Netherlands.

\section{MATERIALS AND METHODS}

Population samples. This study was part of a large epidemiological survey in a Dutch town of c. 60000 inhabitants (Hofman and Valkenburg, 1980). Between 1975 and 1978 invitations to participate in that survey were issued to 13500 people $>6$ years old in two districts of the town, and $10500(78 \%)$, belonging to 4600 households, responded. By random selection 917 of these, all from different households, were chosen for the present survey in such a way as to give roughly equal numbers of children (6-17 years), young adults (18-49 years) and older people ( $\geqslant 50$ years). For each of these we had information about (1) the use of antibacterial drugs within the 30 days before the faecal sampling, (2) hospital discharge within the 3 months before the survey, and (3) connections with cattle breeding. The investigations described here were performed in a 26-month period between September 1978 and November 1980, by which time some of the 917 people were no longer available (see later). An additional study population of children $<6$ years old was obtained from an infant and child welfare clinic in another town, comparable to the first town in size and setting but $c .10 \mathrm{~km}$ from it and nearer to the laboratory. Consecutive mothers bringing their children to this clinic between April and November 1980 were asked to allow us to examine faecal samples from their children; all cooperated. Mothers and children visiting a child welfare clinic are to some extent self-selected, but in The Netherlands the attendance rate is $>90 \%$ for children under one year of age and approx. $75 \%$ for children above that age.

Faecal samples. One faecal sample was collected from each subject by swabbing a freshly passed stool. Swabs were stored in Amies's transport medium for no more than $24 \mathrm{~h}$. Each swab was transferred to a tube containing $10 \mathrm{ml}$ of $0.9 \% \mathrm{NaCl}$, and dilutions of $10^{-3}-10^{-5}$ were made. Standard drops $(0.05 \mathrm{ml})$ of these dilutions were placed on MacConkey agar without antibiotic, MacConkey agar with tetracycline $30 \mu \mathrm{g} / \mathrm{ml}$ or ampicillin $40 \mu \mathrm{g} / \mathrm{ml}$, DST Agar (Oxoid) with $0.5 \%$ lysed horse red cells and sulphamethoxazole $100 \mu \mathrm{g} / \mathrm{ml}$, and Iso-Sensitest Agar (Oxoid) with gentamicin $10 \mu \mathrm{g} / \mathrm{ml}$. Colony counts were made after incubation overnight at $37^{\circ} \mathrm{C}$. From the drug-free medium as well as from the drug-containing agar one colony of each morphologically distinct type was selected and identified by the methods of Cowan (1974). If colonies looked similar, they were assumed to be of the same strain. Tetracycline- and ampicillin-containing plates were used for all samples, but for technical reasons sulphamethoxazole- and gentamicin-containing plates were not introduced until the third and tenth month of the survey respectively. Therefore, only $83 \%$ of the samples from people aged 6-80 years were examined for the presence of sulphamethoxazole-resistant organisms and only $26 \%$ for gentamicin-resistant organisms. All specimens obtained from children $<6$ years old were tested with the four drugs.

\section{RESULTS}

Participants. Samples were obtained from 64 welfare clinic children $<1$ year old (infants) and 53 children aged 1-5 years. Of the infants, $41(64 \%)$ had been born in hospital, $15(23 \%)$ in an out-patient clinic and eight $(13 \%)$ at home. Four were breast-fed. Of the 917 people $>6$ years old invited to participate, 114 had moved out of town or had died before the start of this study, and $179(22 \%)$ of the remaining 803 failed to participate $(19 \%, 26 \%, 21 \%$ of those in the three age groups $6-17,18-49$ and $50-80$ years). This left 624 participants $>6$ years old, fairly evenly divided between the three age groups (see table I). Of these, $23(4 \%)$ had used antibacterial drugs in the 
TABLE I

Numbers of faecal samples from people in different age groups that yielded aerobic gram-negative bacilli

\begin{tabular}{|c|c|c|c|c|c|c|}
\hline \multirow[b]{2}{*}{ Species } & \multicolumn{6}{|c|}{$\begin{array}{l}\text { Number (percentage) of subjects from whom the given species } \\
\text { was isolated in age groups }\end{array}$} \\
\hline & $\begin{array}{c}<1 \\
(\mathrm{n}=64)\end{array}$ & $\begin{array}{c}1-5 \\
(\mathrm{n}=53)\end{array}$ & $\underset{(n=193)}{6-17}$ & $\begin{array}{c}18-49 \\
(\mathrm{n}=221)\end{array}$ & $\begin{array}{c}50-80 \\
(\mathrm{n}=210)\end{array}$ & $\begin{array}{c}\text { total } \\
(\mathrm{n}=741)\end{array}$ \\
\hline $\begin{array}{l}\text { All aerobic gram-negative bacilli } \\
\text { Escherichia coli } \\
\text { Klebsiella spp. } \\
\text { Enterobacter spp. } \\
\text { Proteus mirabilis } \\
\text { Proteus, indole-positive } \\
\text { Pseudomonas spp. }\end{array}$ & $\begin{array}{l}61(95) \\
57(89) \\
46(72) \\
15(23) \\
1(2) \\
3(5) \\
0\end{array}$ & $\begin{array}{l}50(94) \\
46(87) \\
16(30) \\
9(17) \\
0 \\
1 \\
0\end{array}$ & $\begin{aligned} 181(94) \\
178(92) \\
23(12) \\
17(9) \\
0 \\
0 \\
3 \text { (2) }\end{aligned}$ & $\begin{aligned} 207(94) \\
205(93) \\
18(8) \\
12(5) \\
2(1) \\
0 \\
4(2)\end{aligned}$ & $\begin{aligned} 196(93) \\
194(92) \\
26(12) \\
13(6) \\
3 \quad(1) \\
0 \\
6(3)\end{aligned}$ & $\begin{aligned} 695(94) \\
680(92) \\
129(17) \\
66(9) \\
6(1) \\
4(1) \\
13(2)\end{aligned}$ \\
\hline
\end{tabular}

previous 30 days and $11(2 \%)$ were involved in cattle farming. Nine had been discharged from hospital recently.

Distribution of bacterial species in faeces. Table I shows the frequency of isolation of gram-negative aerobic bacilli from the faeces of people in different age groups. In all groups, $E$. coli was found in $87-92 \%$ of the faecal samples. Klebsiella and Enterobacter species were found more often in samples from those $<6$ years old than in the rest $(\mathrm{p}<0.001)$. Klebsiella species were isolated from eight out of 12 samples from breast-fed infants - the four mentioned above and eight others not included in the rest of the study. This isolation rate of $67 \%$ is similar to that for all of the infants $(72 \%)$.

Prevalence of drug-resistant $E$. coli. Table II shows the prevalence of resistant $E$. coli in the five age groups. Calculations were confined to faecal samples that contained $E$. coli, and a sample was classified as containing $E$. coli resistant to a drug if there was any growth of that species on the plate containing that drug. No relationship was found between age or sex and carriage of drug-resistant $E$. coli. The overall prevalence of resistant $E$. coli strains was $42 \%$ for tetracycline, $26 \%$ for ampicillin, $46 \%$ for sulphamethoxazole, and $66 \%$ for any one or more of these. Gentamicin resistance was not encountered in this study.

Predominance of drug-resistant E. coli. Table III shows the numbers of samples

TABLE II

Antibiotic-resistant faecal E. coli in samples from different age groups

\begin{tabular}{l|rrrrrr}
\hline & \multicolumn{5}{c}{ Number (percentage) of subjects from whom resistant $E$. coli strains } \\
were isolated in age groups
\end{tabular}

* The percentages shown in these lines are of the numbers tested for sulphamethoxazole resistance in each age group $-<1$ year $57,1-5$ years $46,6-17$ years $156,18-49$ years $181,50-80$ years 154 , total 594 . 
TABLE III

Predominance of antibiotic-resistant E. coli in samples from different age groups

\begin{tabular}{|c|c|c|c|c|c|c|}
\hline \multirow[b]{2}{*}{ Antibacterial drug } & \multicolumn{6}{|c|}{$\begin{array}{l}\text { Number (percentage) of subjects in whom } E \text {. coli strains resistant to } \\
\text { the given drug were predominant in age groups }\end{array}$} \\
\hline & $\begin{array}{c}<1 \\
(\mathrm{n}=57)\end{array}$ & $\begin{array}{c}1-5 \\
(n=46)\end{array}$ & $\begin{array}{c}6-17 \\
(n=178)\end{array}$ & $\begin{array}{c}18-49 \\
(n=205)\end{array}$ & $\begin{array}{c}50-80 \\
(\mathrm{n}=194)\end{array}$ & $\begin{array}{c}\text { total } \\
(\mathrm{n}=680)\end{array}$ \\
\hline $\begin{array}{l}\text { tetracycline } \\
\text { ampicillin } \\
\text { sulphamethoxazole* }\end{array}$ & $\begin{array}{r}6(11) \\
10(18) \\
9(16)\end{array}$ & $\begin{array}{r}10(22) \\
4(7) \\
14(30)\end{array}$ & $\begin{array}{r}22(12) \\
8 \quad(4) \\
30(19)\end{array}$ & $\begin{array}{r}24(12) \\
9(4) \\
36(20)\end{array}$ & $\begin{array}{l}21(11) \\
11(6) \\
27(18)\end{array}$ & $\begin{array}{r}83(12) \\
42(6) \\
116(20)\end{array}$ \\
\hline
\end{tabular}

* see footnote to table II.

from which colony counts of $E$. coli on the drug-containing agar were at least $50 \%$ of those on the control drug-free medium. No differences in frequency of such predominance between the five age-groups were found for tetracycline or sulphamethoxazole, but predominance of ampicillin-resistant $E$. coli was commoner in samples from infants $(18 \%)$ than in those from the other age groups $(4-7 \% ; \mathrm{p}<0.01)$.

Prevalence of drug-resistant E. coli in high-risk groups. As shown in table IV, both tetracycline resistance and sulphamethoxazole resistance were more common among $E$. coli strains from those who had recently taken antibacterial drugs or were involved in cattle farming than among those from the rest of people $>6$ years old. E. coli was isolated from only four of the nine samples from people who had recently been in hospital.

\section{TABLE IV}

Antibiotic-resistant faecal $E$. coli from samples from high-risk groups and from the rest of those aged 6-80 years

\begin{tabular}{|c|c|c|c|}
\hline \multirow[b]{3}{*}{ Antibacterial agent } & \multicolumn{3}{|c|}{$\begin{array}{l}\text { Number (percentage) of subjects from } \\
\text { whom } E \text {. coli strains resistant to the } \\
\text { given drug were isolated in }\end{array}$} \\
\hline & \multicolumn{2}{|c|}{ High-risk groups } & \multirow[b]{2}{*}{$\begin{array}{l}\text { Others aged } \\
6-80 \text { years } \\
(n=547)\end{array}$} \\
\hline & $\begin{array}{l}\text { Antibacterial } \\
\text { treatment } \\
(n=19)\end{array}$ & $\begin{array}{c}\text { Cattle } \\
\text { farming } \\
(n=11)\end{array}$ & \\
\hline $\begin{array}{l}\text { tetracycline } \\
\text { ampicillin } \\
\text { sulphamethoxazole* }\end{array}$ & $\begin{array}{r}12(63) \\
3(16) \\
11(73)\end{array}$ & $\begin{array}{l}9(82) \\
5(45) \\
6(55)\end{array}$ & $\begin{array}{l}219(40) \\
134(24) \\
204(44)\end{array}$ \\
\hline
\end{tabular}

* The percentages shown are of the numbers tested for sulphamethoxazole resistance in each group-“"antibacterial" group 15, "cattle farming" group 11, "others" 465.

\section{Discussion}

A number of earlier studies of the incidence of resistant intestinal flora used methods comparable with our own. Davis and Anandan (1970) showed that antibiotic-resistant coliforms were significantly less common in an isolated ethnic 


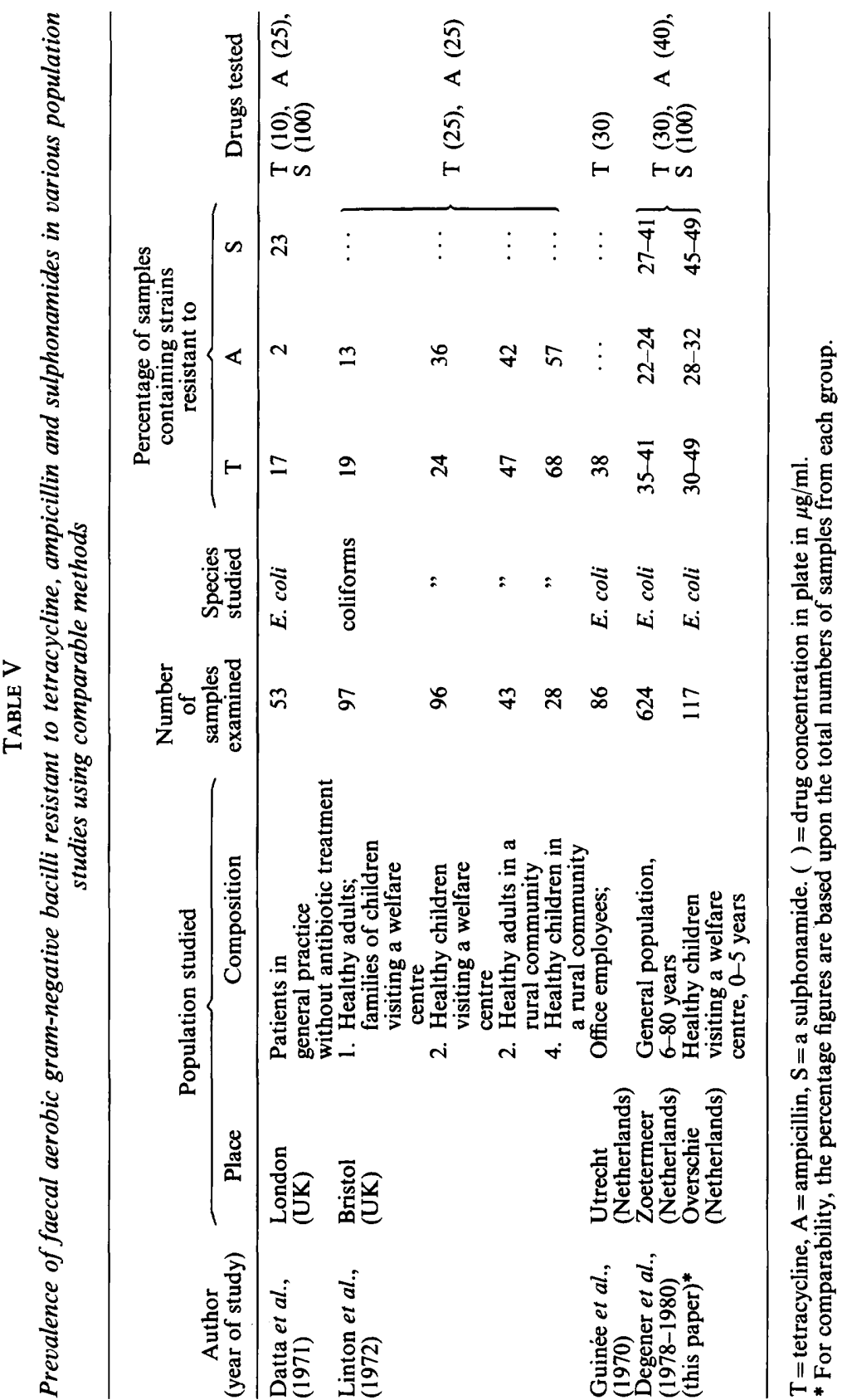


group in Borneo than in Western populations. Unfortunately no figures of antibiotic resistance are available from the pre-antibiotic era in Western Europe. Since the introduction of antibiotics, resistance of intestinal flora has become a common finding both in normal people and in patients not treated with antibiotics. Datta et al. (1971) studied patients who consulted a general practitioner in London and who were not using antibiotics at the time. Her results are listed in table V. Guinée, Ugueto and van Leeuwen (1970), using an agar medium containing tetracycline, observed resistant $E$. coli in samples from $38 \%$ of a group of office employees in Utrecht, a percentage similar to our findings. Linton et al. (1972), in Bristol, isolated more resistant strains from children than from adults, and more from the rural than from the urban population; but they did not differentiate between the various genera of enterobacteria. Our study revealed a significantly higher prevalence of Klebsiella and Enterobacter species in infants. Moreover, we found a higher frequency of ampicillin-resistant $E$. coli strains in the stools of infants than in older children and adults. In general our results, although obtained in urban populations, most closely resemble Linton's findings in the rural population group.

Our most remarkable finding was the lack of correlation between age and the presence of drug-resistant faecal flora, although the age groups must have differed in their exposure to therapeutic antibiotics. The origins of drug-resistant human faecal flora are still obscure. Large scale use of antibiotics in livestock farming has led to multiresistant flora in cattle (Anderson, 1965; Smith, 1968). These resistant strains are readily transmitted to human subjects (Levy, FitzGerald and Macone, 1976). Person-to-person spread can also occur (Petrocheilou, Richmond and Bennet, 1977). Other means of transmission are by faecal contamination of surface waters (Guinée, Sekhuis and Ugueto, 1974) and food products (Shooter et al., 1971; Casewell and Phillips, 1978; Cooke et al., 1979). Finally the use of antibiotics in medical practice can also contribute to carriage of resistant strains (Richmond and Linton, 1980). During our study period general practitioners in the town from which we drew our older children and adults provided, in one year, 33460 sick-fund patients with a total of 18000 prescriptions for antibiotics. These 33000 patients represented approximately 11000 families. Therefore, on average in one year in each family, one or two family members received a full course of antibiotics that might have induced the circulation of resistant faecal strains. Tetracyclines were included in $20 \%$ of these prescriptions. If we assume that excretion of tetracycline-resistant strains lasted for 2 weeks after each prescription, this represents an annual total of 50400 patient-days or an average of 4.5 days of excretion per household. This seems insufficient alone to account for our finding that $42 \%$ of $E$. coli strains were tetracycline-resistant.

Another interesting finding was that the prevalence of Klebsiella and Enterobacter species, which are commonly drug-resistant, was highest among infants and decreased with age. Feeney, Cooke and Shinebaum (1980) reported a higher incidence of resistant flora, including Klebsiella species, in bottle-fed than in breast-fed children. We could not confirm this, but our number of breast-fed infants was small.

This study was supported by a grant from the Dutch Prevention Fund. We thank the people and the general practitioners of Zoetermeer for participating in this study. We are grateful to Mrs J. J. de Graaf-Hoedemaker and the personnel and visitors of the infant welfare centre in Overschie for their cooperation. We are indebted to Dr P. A. M. Guinée for his advice and to Miss L. P. C. Harkes for typing the manuscript. 


\section{REFERENCES}

ANDERSON, E. S. 1965. Origin of transferable drug-resistance factors in the Enterobacteriaceae. British Medical Journal, 2, 1289-1291.

Brumfitt, W., Faiers, M. C., Reeves, D. S., and Datta, N. 1971. Antibiotic-resistant Escherichia coli causing urinary-tract infection in general practice: relation to faecal flora. Lancet, 1, 315-317.

Casewell, M. AND PhILlips, I. 1978. Food as a source of Klebsiella species for colonisation and infection of intensive care patients. Journal of Clinical Pathology, 31, 845-849.

CoOKe, E. M., Brayson, J. C., Edmondson, A. S. AND Hall, D. 1979. An investigation into the incidence and sources of Klebsiella infections in hospital patients. Journal of Hygiene, Cambridge, 82, 473-480.

Cooke, E. M., Sazegar, T., Edmondson, A. S., Brayson, J. C. and Hall, D. 1980. Klebsiella species in hospital food and kitchens: a source of organisms in the bowel of patients. Journal of Hygiene, Cambridge, 84, 97-101.

Cowan, S. T. 1974. Cowan and Steel's Manual for the identification of medical bacteria, 2nd ed. Cambridge University Press, Cambridge.

Datta, N., Faiers, M.C., ReEves, D.S., Brumfitt, W., Örskov, F. and Örskov, I. 1971. R factors in Escherichia coli in faeces after oral chemotherapy in general practice. Lancet, 1 , 312-317.

Davis, C. E. And Anandan, J. 1970. The evolution of R factor. A study of a "preantibiotic" community in Borneo. New England Journal of Medicine, 282, 117-122.

FEENEY, A. R., COOKE, E. M. AND ShINEBAUM, R. 1980. A comparative study of gram-negative aerobic bacilli in the faeces of babies born in hospital and at home. Journal of Hygiene, Cambridge, 84, 91-96.

GRÜNEBERG, R. N. AND SHAw, E. J. 1976. The influence of antibiotic treatment on resistance patterns of coliform bacilli in childhood urinary-tract infection. Journal of Medical Microbiology, 9, 233-237.

Guinée, P. A. M., Ugueto, N. ANd van Leeuwen, N. 1970. Escherichia coli with resistance factors in vegetarians, babies and nonvegetarians. Applied Microbiology, 20, 531-535.

Guinée, P. A. M., Sekhuis, V. M. and Ugueto, N. R. 1974. Escherichia coli met resistentiefactoren in effluenten en oppervlaktewateren. Tijdschrift voor watervoorziening en afvalwaterbehandeling, 8, 156. (in Dutch).

Hofman, A. AND VAlKenburg, H. A. 1980. Distribution and determinants of blood pressure in free-living children. In Epidemiology of arterial blood pressure, edited by $\mathrm{H}$. Kesteloot and J. V. Joossens; Developments in cardiovascular medicine, 8, Martinus Nijhoff, The Hague, pp. 99-117.

Levy, S. B., FitzGerald, G. B. AND Macone, A. B. 1976. Changes in intestinal flora of farm personnel after introduction of tetracycline-supplemented feed on a farm. New England Journal of Medicine, 295, 583-588.

Linton, K. B., Lee, P. A., Richmond, M. H., Gillespie, W. A., Rowland, A. J. ANd BaKer, V. N. 1972. Antibiotic resistance and transmissible R-factors in the intestinal coliform flora of healthy adults and children in an urban and a rural community. Journal of Hygiene, Cambridge, 70, 99-104.

Petrocheilou, V., Richmond, M. H. and Bennet, P. M. 1977. Spread of a single plasmid clone to an untreated individual from a person receiving prolonged tetracycline therapy. Antimicrobial Agents and Chemotherapy, 12, 219-225.

Richmond, M. H. AND Linton, K. B. 1980. The use of tetracycline in the community and its possible relation to the excretion of tetracycline-resistant bacteria. Journal of Antimicrobial Chemotherapy, 6, 33-41.

Shooter, R. A., Faiers, M. C., Cooke, E. M., Breaden, A. L. and O'Farrell, S. M. 1971. Isolation of Escherichia coli, Pseudomonas aeruginosa, and Klebsiella from food in hospitals, canteens, and schools. Lancet, 2, 390-392.

SмIтH, H. W. 1968. Anti-microbial drugs in animal feeds. Nature, 218, 728-731. 